\title{
It is Indeed Time to Focus on Ai Based Image Recognizing App to Boost the Self-Confidence of the Visually Challenged in the Indian Context
}

\author{
Neha Patvardhan, Smita Santoki
}

\begin{abstract}
Purpose: Artificial intelligence (AI) will be at the forefront of any modern communication in the future, so this research is carried out to find out the strengths and limitations of the AI based image recognizing app (AI poly) for the visually impaired people and also to assess the self-confidence of such people before and after using the app
\end{abstract}

Methodology: 40 visually impaired people from the Atmadeepam Society (Nagpur, India) who are computer educated and smartphone users considered for the study using mixed research methods. For measuring the app usability, InApp survey is undertaken and for finding the self-confidence; ASCI inventory is done

Findings: More than $80 \%$ of the respondents are satisfied with the app however; this does not hold true for the Indian food items recognizing feature of the app as the satisfaction is as low as $63 \%$.

There is a marginal improvement seen in their self-confidence post regularly using this app for three months

Practical Implications: It is evident from the findings that these visually impaired people are extremely happy in using this AI poly app to overcome their navigation challenges and get confidence in doing their own things independently On the other hand, research finding also shows a set of people who are not convinced fully with the AI based apps functioning. These were typically based on incorrect object identification, difficulty in understanding the accent of the voice assistants

Social Implications: The visually impaired will be better equipped to function due to increased confidence, positive attitude and thus gaining a place in society as an active contributor to the economy, which will contribute to the Disabilities integration

Originality / Value: The paper attempts to study modern AI accessibility applications for visually impaired persons, in particular related to object recovery in the Indian context. And to assess their self-confidence post using the app.

Keywords: Artificial Intelligence (AI), App(s), Image Recognition, Self-confidence, Visually Impaired and Indian context

\section{INTRODUCTION}

A right kind of positive attitude along with confidence can set any planned mission in to an action. And this confidence gets all the more utmost importance when this is in the case of a person with a disability. As anything, he or she gathers to gain is solely dependent on his/her motivated spirit. In today's fast-paced life where technology is getting innovative and advancing in terms of speed and accuracy; even the visually impaired is able to lead a comfortable life with the AI Based apps around build in for their comfortable navigation.

One such app is the AI based AI poly app that is assisting the visually disabled in both indoor and outdoor navigation with ease. According to Julie Deden (Executive Director of the Colorado Centre for the Blind), "Apple has done such a tremendous job with their products and the accessibility is built directly to the phones." The blind can just put the Voiceover on and the touchscreens get talking to them; thereby giving the blinds too a taste of the modern technology and letting them too eat the pie of these AI based app's success.

The limiting factor however is in the Indian context as the app's image recognition does not give out the correct Indian names of the objects and at times is clueless about certain important Indian food items which can be misleading at most of the times. Especially for the visually challenged as they are big time dependent on these voice assistants for their basic needs.

Therefore, it is of prime importance to study the usability of such image recognizing apps like AI poly for the Indian visually disabled.

\section{LITERATURE REVIEW}

There are 2 main kinds of assessments in contemporary studies of individual differences in confidence namely judgements of accuracy and personality-like self-report questionnaires designed to assess one's belief in his/her ability to finish the tasks (Stankov, Kleitman, \& Jackson, 2015) Cognitive technologies is of the most practical relevance for accessibility to be successful. Moreover, this gets a double whammy if not done well in case of the blind. Everything right from their first step indoors to moving out depends on a guide; be it in the form of a sighted person, a walking cane or the modern day mobile gadget streaming with latest updated apps.

A report by Accenture says, "AI has the potential to add $\$ 957$ billion or $15 \%$ of current gross value added, to India's economy in 2035."
Revised Version Manuscript Received on August 19, 2019.

Dr. Neha Patvardhan, Assistant Professor, Symbiosis Institute of International Business, Pune; Maharashtra, India. (Email: neha.patvardhan@siib.ac.in)

Ms. Smita Santoki, Assistant Professor, Symbiosis Institute of International Business, Pune; Maharashtra, India (Email: smita.santoki@siib.ac.in) 


\section{IT IS INDEED TIME TO FOCUS ON AI BASED IMAGE RECOGNIZING APP TO BOOST THE SELF-CONFIDENCE OF THE VISUALLY CHALLENGED IN THE INDIAN CONTEXT}

According to a paper by research firm IDC and storage company Seagate, "Global data will grow from 33 zetabytes (1ZB is 1 trillion gigabytes) in 2018 to $175 \mathrm{ZB}$ by 2025 . The accuracy of AI systems increases with larger amounts of data. And given its large population and massive amounts of data, India is a fertile ground for developing better AI systems." (Business Standard newspaper article dated 30 Jan 2019) Research provides various insights to know a visually impairer's challenges. Like (Melarkode, 2014) "using a scenario-driven, ontological and goal-oriented approach. In-house testing conducted revealed that collaborative approach may indeed provide added comfort during indoor navigation."

Or the paper by (Liao, 2016) where they have mentioned about the differences in the sighted people and the visually challenged with reference to their spatial perception where the VI person usually face physical as well as information barrier. For their accessibility, mobility and confidence boosting, the researchers have given stress on improving the transport system and thus have come up with a mobile accessible information system that allows visually challenged people to receive information related to their transportation at key junctions.

They came up with a personal assistive system based on a smartphone called MAPS (Mobile Accessible Pedestrian System), that provides intersection geometry and signal timing information. "Research has been carried out through smart phone application to support visually impaired pedestrians at signalized intersections crossings" (Liao, 2013)

We also appreciate the work done by (Rahman \& Hassan, 2002) where they address the aid for visually impaired and blind people for portable mobility. The aim of the research is to find out a matching algorithm for object detection for moving image sequences.

Another algorithm based study is done by (Tumkur \& Subbiah, 2012) on Pedometers. These devices consist of measuring distance covered by the number of steps taken by an algorithm. Further accelerometer wise they have worked currently existing models.

Another attribute about the visually impaired is about their physical activity studied by (Marmeleira, Laranjo, Marques, \& Pereira, 2014) where they compared them to the sighted people with the help of the accelerometers to monitor their daily physical activity for one week. They concluded that there was no difference in gender and that the body mass index not associated with physical activity. Their conclusion gives health promotion strategies required for the visually handicapped as they have low levels of physical activity.

Alternatively, a study done by (Paisios, 2012) the researchers present a simple to use mobile navigational guide for the visually challenged in their indoor navigation set up. Another work by them in the Mobile Brailler that has the prototypes to enter text to a mobile smart phone that is based on the Braille alphabet. Then they have worked in getting currency bills readable tool easily by the disabled. And have also worked on their ease of understanding the color combinations to be worn.

Internationally speaking, plethora of work is available on AI based Apps related to accessibility for the visually upon the results to find out any differences with respect to

impaired community; however very negligible data and work exists in the Indian context; especially for the image recognition apps that the blinds of Indian soil may require.

Varun Aggarwal of Aspiring Minds points out so well when he says," The country's diversity of languages, dialects, accents, scripts, dress and culture presents a rich set of challenging problems for AI. Current AI techniques are limited in their ability to handle complexity, and they will have to mature to deal with the diversity of life in India."

Our study aims at investigating whether a visually impaired person is comfortable using the AI poly app and if the image recognition feature is of good use to them in the Indian set up.

In accord with the same, there have been studies and research undertaken; however big breakthroughs are required to be done in the Indian context as only one app so far is trying to manage to suit the needs of the Indians concerning the object recognition app.

The above-mentioned app is the pioneer innovation undertaken by Accenture Labs, Accenture; India. This app is launched just the last year and is still in its pilot phase. Moreover, it has studied in general and yet to be tested for people with special needs. "Drishti leverages latest artificial intelligence (AI) technologies, including natural language processing, image recognition, optical recognition, and smart glasses to help visually-impaired persons perceive the world around them like never before." (Kapur 7 Kapur, 2014)

Thus, our research paper is uniquely strategized at finding out the limitations of this app in identifying the local Indian words for the objects recognizing feature and suggestions accordingly to improvise it.

And for study of self-confidence, most of the literature review gives out the ASCI test (Agnihotri's Self-Confidence Inventory) of 56 items to find out the self-confidence.

(Ahmad, 2015)

\section{RESEARCH GAP}

Past research focuses on accessibility in terms of navigation, mobility, walking speed, physical activity, touch screen braille texts, etc. However, the element missing in the past search is the study in the Indian context of AI apps from the visually impaired point of view, especially their experience of the app in navigation and what wonders it has done and can further do to their boost in self-confidence

\section{OBJECTIVES}

a. To analyse the user experience of the 'image recognising' AI poly App for accessibility of the visually impaired in India

b. To study the limitations of the object recognizing app in the Indian context

c. To enlist possible suggestions that can be done to improve the object recognition app AI poly in the Indian context

d. To find out the self-confidence levels of the subjects after using AI poly app for

a regular period of 3 months 


\section{HYPOTHESIS FOR SET-I}

e. H0 - Indian Visually impaired are satisfied using the image recognition based

AI Poly app

f. H1 - Indian Visually impaired are not satisfied using the image recognition

based AI Poly app

\section{HYPOTHESIS FOR SET-II}

a. H0 - There is a marginal improvement in the self-confidence of the visually impaired post using the AI based AI poly app

b. H1 - There is no marginal improvement in the self-confidence of the visually impaired post using the AI based AI poly app

\section{METHODOLOGY}

\subsection{Research Methodology}

Post the study on usability of the AI based image recognizing app AI poly for the visually challenged from India; the authors are extending this research to gauge whether there is an increase in their self-confidence post using this AI app.

Forty visually impaired Indian young adults (18-40 years age group) who are both computer literate and smart phone users considered for the study to find out if they had boost in their self-confidence post undergoing this experiment for few weeks.

This experiment conducted in two sets. One, as a questionnaire form to find out the app usage amongst these visually impaired to find out the advantages and limitations of the app for these subjects' in the Indian context.

And the second one undertaken to find out the change in their self-confidence post the app usage; assessed through the Agnihotri's Self-Confidence Inventory (ASCI) undertaken at regular intervals of each month (consecutively for three months).

Therefore, the researchers take mixed methodology approach. Phenomology method through verbatim is also considered.

\subsection{SET-I (Usability test of AI poly)}

For set 1 , the AI app usability study taken under three phases, namely phase one where one day briefing regarding how to use the AI Poly app was provided to the visually impaired to get them accustomed to the app.

Next phase, they were asked to use the app for their indoor-outdoor navigation purpose for a week accompanied by a sighted person to note the observations.

During this they got introduced to the below mentioned item categories to maintain the homogeneity of the study:

(1) Personal Care objects

(2) Labelling on medicines and health care monitoring systems

(3) Time keeping Tools

(4) Alarming tools

(5) Food preparations

(6) Consumption utensils

(7) Currency and finance operations

And in the last phase the researchers gathered the responses of the subjects' to find out the advantages and the limitations of the app for these disabled group through the 5 point Likert scale of Satisfaction for the following constructs:

(1) Ease of App navigation and exploration

(2) Swift Switching over to the other menu for different object categories

(3) Comprehensiveness of the settings

(4) Accuracy in Object, text and colour recognition

(5) Time lag in navigation

(6) Speediness of the APP

Feedback from the sighted escorted person is according to the different category of objects as follows:-

(1) Correct identification of the personal Care objects

(2) Correct identification of the labelling on medicines and health care monitoring systems

(3) c) Correct identification of the time keeping Tools

(4) d) Correct identification of the food preparations

(5) e)Correct identification of the consumption utensils

(6) Correct identification of the currency and finance operations

The set-I experiment took three months to complete

For the qualitative analysis, the verbatim relating to the feedback and suggestions for an improvement in the App in the Indian context were recorded and have been analyzed in the Data analysis and interpretation

\subsection{SET II (Assessing change in self-confidence)}

Before carrying out the set 1 experiment; the subjects' self-confidence levels were known by the ASCI test.

Later on, post the Set-I experiment, the researchers repeated the same test every month end for three months consecutively to get the self-confidence known of the Indian visually impaired. This test taken is also by the Agnihotri's Self-Confidence Inventory (ASCI) that consists of 56 questions that includes items for the assessment of self-confidence.

Each of this item are marked by the participants under study related in the context of the app under investigation

"The author has given the following classification criteria:

\begin{tabular}{|l|l|}
\hline Raw Score & Explanation \\
\hline 7 and below & $\begin{array}{l}\text { Very High Self- } \\
\text { Confidence }\end{array}$ \\
\hline $8-19$ & $\begin{array}{l}\text { High } \\
\text { Self-Confidence }\end{array}$ \\
\hline $20-32$ & $\begin{array}{l}\text { Average } \\
\text { Self-Confidence }\end{array}$ \\
\hline $33-44$ & $\begin{array}{l}\text { Low } \\
\text { Self-Confidence }\end{array}$ \\
\hline 45 and above & $\begin{array}{l}\text { Very Low Self- } \\
\text { Confidence }\end{array}$ \\
\hline
\end{tabular}

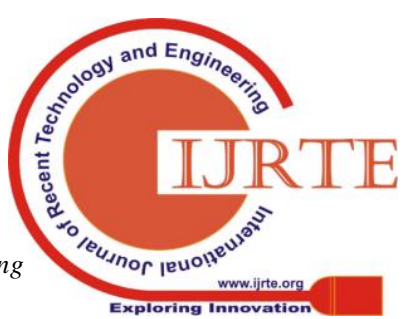




\section{IT IS INDEED TIME TO FOCUS ON AI BASED IMAGE RECOGNIZING APP TO BOOST THE SELF-CONFIDENCE OF THE VISUALLY CHALLENGED IN THE INDIAN CONTEXT}

\section{Scoring:}

The inventory is scored by hand. A score of one is awarded for a response indicative of lack of Self-Confidence, i.e for making cross $(\mathrm{X})$ to a wrong' response to item numbers $2,7,23,31,40,41,43,44,45,53,54,55$ and for making cross (X) to right' response to the rest of items. Thus each item has a maximum score of " 1 " and minimum of " 0 " and response value of which extend from 0-56.

Hence the lower the score, the higher would be the level of self-confidence and viceversa." (Des, Unis, \& Washington, 2015)

A standardized scale has 0.88 reliability. And Validity is 0.83

\subsection{Sample Size}

As per the literature review available the average number of sample size lies between 20-40 for such studies. And as this study is based on the visually disabled who were both computer literates and smart phone users, the sample size 40 looks relevant. Hence, the researchers assume the sample size to be normal.

\section{DATA ANALYSIS \& INTERPRETATION}

\subsection{For SET-I Experiment:}

As per the InApp Survey conducted, more than $80 \%$ of these visually impaired respondents are satisfied with the said app for indoor and outdoor navigation and other related constructs.

Table 1.

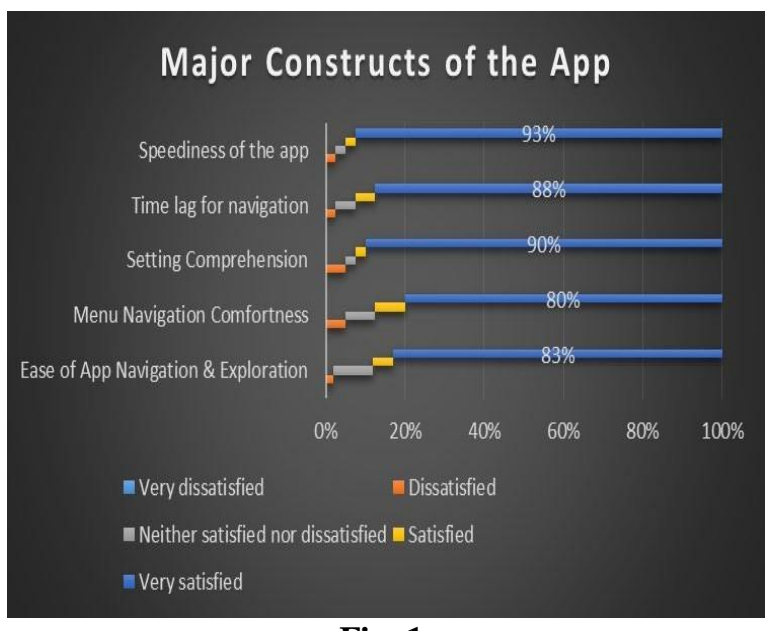

Fig. 1.

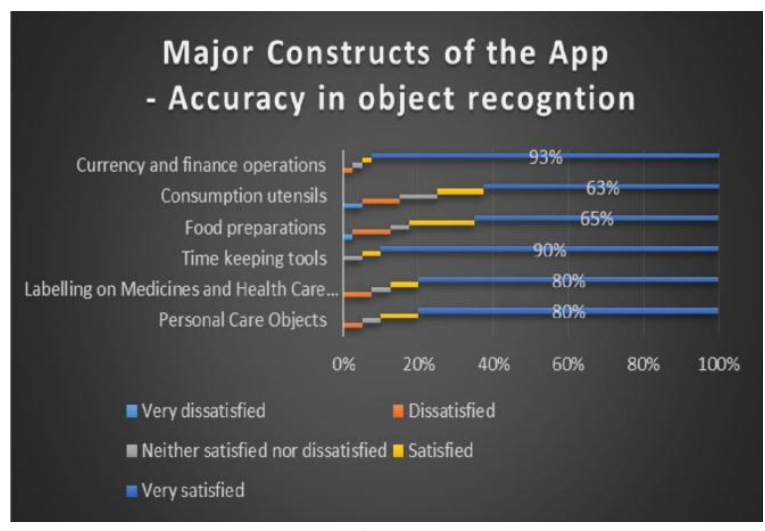

Fig. 2.

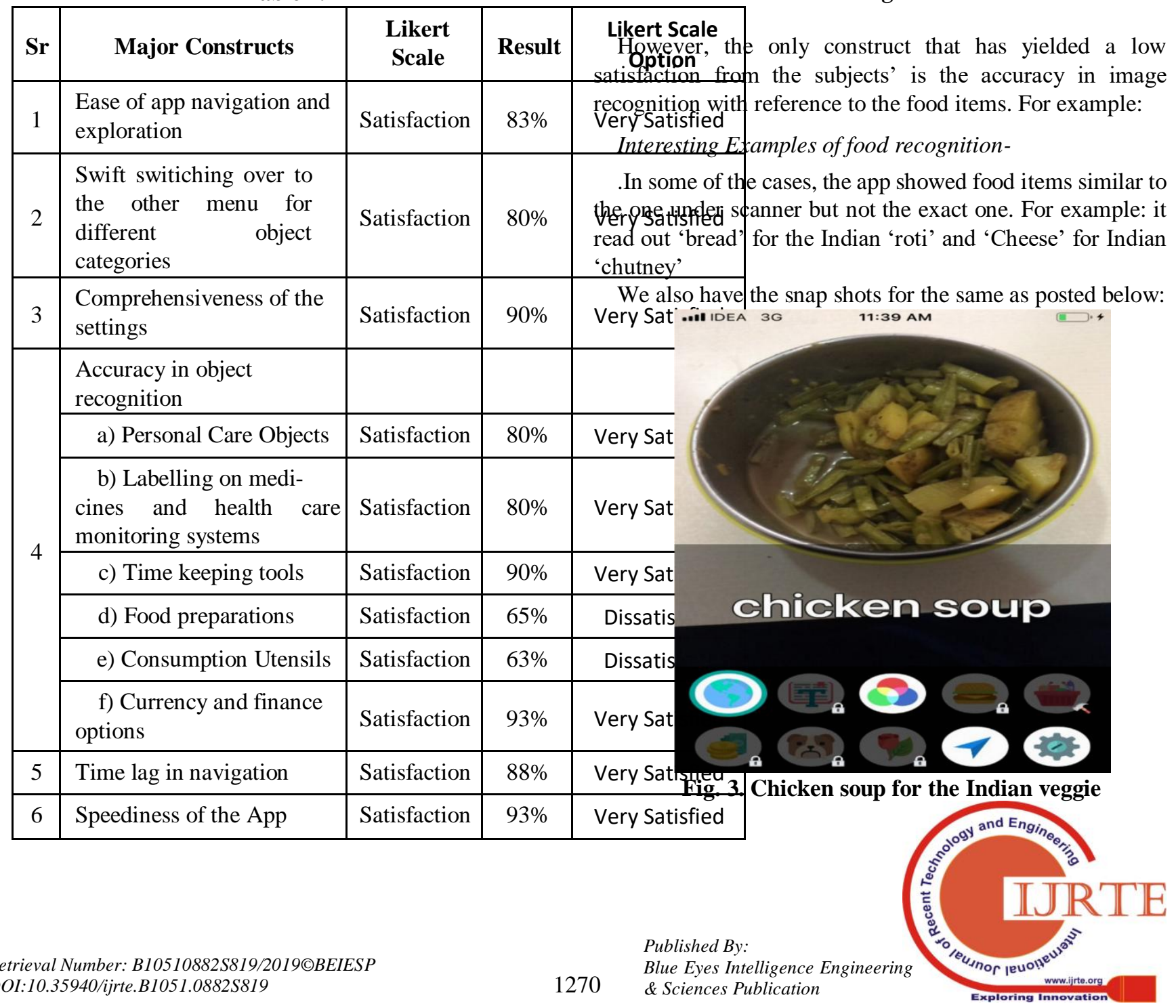




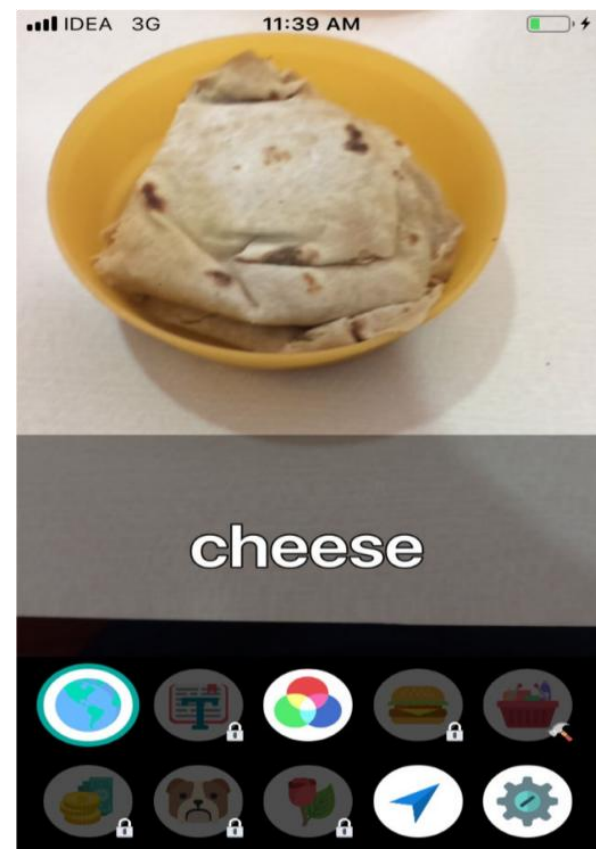

Fig. 4. Cheese for the Indian roti

\subsection{Analysis through Verbatim (For Set-I Experiment)}

From the above analysis, it is clearly seen that in terms of identifying, the correct object is a challenge in the Indian sense and this is further validated with the phenomology method undertaken through verbatim from the respondents:

Sonali, 20yrs:. "I cannot understand the accent of the voice assistant who guides me through the app; so I want someone to replace her with a language that I can understand."

Dilip, 26yrs: "It was a very useful experience to know how I can do things faster with this app. I wish to use this app daily now for my navigation purpose.".

Mayur, 28yrs: "I made the right choice by downloading the AI poly app, post our research experience at Anandeepam. This app has simplified my life from the various day-to-day challenges I encountered earlier due to my disability. Now, not only am I able to function smoothly, both indoors and outdoors with this AI ply but I have gained good vocabulary through the app."

Geeta,18yrs: "I cannot afford the iOS phone right now but thanks to your experiment time that I could see how usefully this works. The app is very user friendly and provides the switching off different menu settings faster."

Parikshit,21yrs: "I didn't know this AI poly app to be so useful to us. I have used both its text recognition feature as well as the object recognition app and find both of them extremely beneficial."

Apeksha,20yrs: "Initially I thought this app will be of limited help but when I tested it every day regularly for a week, got to know its features and applications in details. The only big limitation I find in this app is that it is unable to identify our Indian grocery items like lentils, flour, pickles etc and so I want to suggest that they can work on an algorithm that picks up vernacular languages also so that this is a convenience tool that can be used in the Indian context."

Sneha,21yrs: "I am skeptical about this app as I feel this is not made for people of India. The other day, I could not get 'amrutanjan' (an Indian name for a balm that cures headache) for my grandmother when she asked me to get it. The object recognition simply could not understand what the object was and kept on beaming, 'am not sure' so they must make the app user friendly in the Indian context.".

Kapil,24yrs: "it is my pleasure that I was a part of this study. My teacher and the researchers explained us the app functioning very clearly. I could use it well for a week of the study. I have bought the apple phone and downloaded the AI poly app that will now ease out my daily functioning significantly. I can now mix with my sighted friends with comfort."

Kunal,38yrs \& Savita,36yrs: "The object recognition tool failed to guess our staple Indian food items like 'rotis', 'daal', 'sabzi', 'chawal' etc. and we had tough time serving the same to our guests. The AI systems must work upon an app that will have Indian objects recognized."

Nimisha,31yrs: " Food items, medicines and few household Indian items are not recognized by the object recognition app so such research must happen in the Indian set up to benefit people like us.".

Prerna,30yrs: "This app is not very useful for us as mainly we need app for identifying the objects we use for day to day activities so except for a few objects, majority of our Indian things are not recognized by app."

Neelam,19yrs: "There are many accessibility apps available for us in the market but this one is great in terms of speed in speech texts recognition but lacks object recognition for us Indians.".

Yatin,21yrs: "Customization to vernacular Indian languages needed for us to in terms of object recognition app so that we can decipher the signals, objects and various texts easily."

. Sana,20yrs: "I find a lot of difficulty in understanding the signboards as the App does not read out my vernacular language (Marathi) and thus causes a lot of hindrance in outdoor mobility.".

Zubin,22yrs: "I could not pick up the band aid as it could not identify the local name."

Yamini,23yrs: "The App could not read out the vernacular newspaper text to me and so I could not participate for an essay competition.".

Lata,24yrs: "AI App is of significant importance to visually challenged people like us because we get a feeling of someone accompanying us for our daily navigation purpose and acts as a strong catalyst for connecting us to the general public."

Parag,40yrs: "Although late, but I am glad I got to know this App that is not only useful but has given an opportunity to use and provide our feedback to the researchers."

Asha,39yrs: "Accessibility Apps like these are required to be customized to the Indian customers need so that the Company can get access to one of the largest markets in the world."

Akhil,23yrs: "I look forward to use this App for the next six months and come up with a lot of possible ideas to improvise it to suit the Indian conditions."

Therefore, Hypothesis $\mathrm{H} 0$ cannot be rejected as almost $80 \%$ of the respondents are satisfied with the app usage. 


\section{IT IS INDEED TIME TO FOCUS ON AI BASED IMAGE RECOGNIZING APP TO BOOST THE SELF-CONFIDENCE OF THE VISUALLY CHALLENGED IN THE INDIAN CONTEXT}

\subsection{For SET-II Experiment:}

The ASCI test was conducted four times i.e once at the Set-I Experiment stage and the other three were conducted sequentially after Set-I at the end of each month (therefore for 3 months). The average raw scores for the ASCI is as follows:

\begin{tabular}{|c|c|c|}
\hline $\begin{array}{c}\text { Serial } \\
\text { Number }\end{array}$ & $\begin{array}{l}\text { Time Period for } \\
\text { ASCI }\end{array}$ & $\begin{array}{c}\text { Average } \\
\text { Raw } \\
\text { Scores }\end{array}$ \\
\hline 1 & $\begin{array}{l}\text { Before Set-I } \\
\text { Experiment }\end{array}$ & 36 \\
\hline 2 & After 1 month & 33 \\
\hline 3 & After 2 months & 30 \\
\hline 4 & After 3 months & 27 \\
\hline
\end{tabular}

As per the findings, prior to the set-I experiment the disabled subjects carried a low confidence of average score 36 that falls under the range of 33-44 for low confidence as per the ASCI scale (Dr Rekha. Agnihotri's) Then post Set-I Experiment; at the end of 1st month, there is a slight decrease to 33 in the raw score average; still depicting low confidence but just at the border.

At the end of the 2nd month, this score further came down to 30 and at the end of the third month it showed 27 clearly showing the shift to an improvement in their self0confidence; although marginally after using this app regularly. Therefore for setII hypothesis H0; is not rejected.

\section{FINDINGS \& SUGGESTIONS \& RESULTS}

The major findings that emerge from the analysis is that the artificially intelligent based AI Poly app is overall a very useful resource for the visually challenged with a setback found majorly in their object recognition feature only in the Indian context.

High customization is the relevant need of the hour for the app like AI Poly to suit the specific local needs of the visually disabled when they need the object recognition app to give out the exact Indian version of the products especially in the food and consumption utensils category.

For instance, when an Indian blind wants to know the medicines available locally, the app based guide prompts as 'Not sure' and this happens repeatedly for many Indian products in food, grocery items, personal care, health care as well as the sign boards while he/she moves outside.

In this study, it is observed that almost $80 \%$ of the participants were satisfied with almost all the parameters undertaken for the study, namely

(a) ease of app navigation and exploration

(b) Swift switching over to other menus for different object category

(c) Comprehensiveness of the settings

(d) Time lag for navigation

(e) Speed of the app

Except for the object recognition feature where only the food and the consumption utensils category has not much clarity as compared to the other categories under objects recognition tabs and this is clearly so in the Indian local cases.
Verbatim collected through phenomology method also reflected the above findings through the observations, suggestions and feedback by the focused group.

In the set-II experiment on checking the self-confidence of the subjects' post the usage of the app regularly; a marginal improvement has been observed in the study through the ASCI Inventory. And thus, it becomes significant on behalf of these AI tool builders to focus their attention to these needs too

Therefore, we would like to suggest probable solutions for the pain points of the Indian visually impaired that needs to be urgently addressed to by the AI based app developers, technocrats, technical experts and such decision makers. Our suggestions are as follows:

They need to add the Indian image repository to the app especially the food segment and the consumption utensils section

As per the snap shots provided under findings, few Food items identified by the object recognition app is not the exact one but falls under the food items category itself. Thus, our suggestion is to improve this by adding food image repository

For vernacular Indian languages to be identified by the voice assistants, the AI and the deep learning algorithms should bring a smart curation of content in their regional languages for example: Sign boards instructions in local language

And vernacular Indian language translations similarly for the text recognition feature also required

And there can be a direct proportional change in their self-confidence if the above changes get implemented as self confidence boost can trigger the best and more use of the app. This is typically required in the Indian set up

\section{LIMITATIONS \& FUTURE SCOPE FOR RESEARCH}

The research is limited to the AI Poly app and not the other smartphones apps. Secondly, the study is restricted specifically to the needs, usage and limitations for the Indian visually challenged persons. The researchers also had limitations to the subjects involved as they have limited it to the number as 40 and that too to only those who are computer literates and smart phone users.

And for measuring self-confidence; the researchers restricted their study to just three intervals at three months only.

Limitations however pave the way for the future scope of research in a way and so this research work can be extended to a larger group of data. This can be extended to the education of such people through incorporating this to Education 4.0. And if this works for them in the Indian context, this research can be extended to the other similar neighbouring cultures

\section{CONCLUSION}

The past is not an indicator to the future because the progress and the growth story in AI, machine learning, computing power and robotics have changed the way things

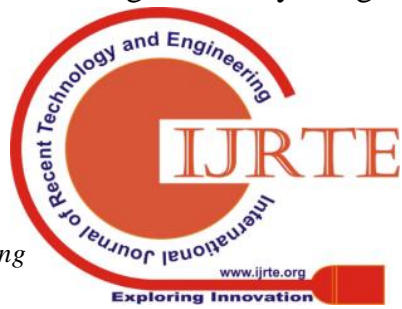


are done in the most dramatic way. The accessibility landscape is going strong but needs a lot of rework in the Indian context.

AI poly need not reform but needs to transform and weave the matrix in such an algorithm that it will be perfectly applicable to Indian roots.

The efforts taken by the team at Apple to make AI poly app will be realized in one of the largest markets of the world, India; when it is made meaningful to its end users.

More so in case of the visually challenged as they must have apps that provide them the correct object identification name as they move around looking for their daily needs.

The way advances in vision recognition allow robots to identify objects and wide range of applications, same way the AI should technologically advance.

AI needs to be designed and be more adaptive to the Indian consumers as this is where one of the largest population of the world resides.

Rapid progress in digital technologies and given the increasing use of technology and smart devices, there is a huge opportunity to create an impact through better usage experiences.

Our attempt may be just a granular bite of knowledge on the topic of concern but can be further enhanced by extending it to the other disability groups for an all-inclusive diverse India

\section{REFERENCES}

1. Liao, C.-F. (2013). Using a Smartphone Application to Support Visually Impaired Pedestrians at Signalized Intersection Crossings. Transportation Research Record: Journal of the Transportation Research Board. https://doi.org/10.3141/2393-02

2. Liao, C.-F. (2016). An Integrated Assistive System to Support Wayfinding and Situation Awareness for People with Vision Impairment. ProQuest Dissertations and Theses.

3. Marmeleira, J., Laranjo, L., Marques, O., \& Pereira, C. (2014). Physical activity patterns in adults who are blind as assessed by accelerometry. Adapted Physical Activity Quarterly, 31(3), 283-296. https://doi.org/10.1123/apaq.2013-0039

4. Melarkode, S. G. (2014). THEIA: A collaborative, indoor impaired. ProQuest Dissertations and Theses.

5. Rahman, S., \& Hassan, Q. K. (2002). Object detection with vision based system: A secondary aid for visually impaired and blind people. In 6TH WORLD MULTICONFERENCE ON SYSTEMICS, CYBERNETICS AND INFORMATICS, VOL IX, PROCEEDINGS: IMAGE, ACOUSTIC, SPEECH AND SIGNAL PROCESSING II.

6. Gayathri, G., Vishnupriya, M., Nandhini, R., Banupriya, M., Al-barrm, O. B., Ersen, A., ... Alkunte, S. (2014). Smart Walking Stick for Visually Impaired. International Journal Of Engineering And Computer Science. https://doi.org/10.1371/journal.pone.0015995

7. Terven, J. R., Salas, J., \& Raducanu, B. (2014). New Opportunities for computer visionbased assistive technology systems for the visually impaired. Computer. https://doi.org/10.1109/MC.2013.265

8. White, G. R., Fitzpatrick, G., \& McAllister, G. (2008). Toward accessible 3D virtual environments for the blind and visually impaired. In Proceedings of the 3rd international conference on Digital Interactive Media in navigation, smartphone application, for the visually

Entertainment and Arts - DIMEA '08. https://doi.org/10.1145/1413634.1413663

9. Kapur, A., \& Kapur, S. (2014). Drishti: An ultra-low cost Visual-Aural assis-tive technology for the visually impaired. In i-CREATe 2014 - international Con-vention on Rehabilitation Engineering and Assistive Technology.

10. Tumkur, K., \& Subbiah, S. (2012). Modeling human walking for step detection and stride determination by 3 -axis accelerometer readings in pedometer. In Pro-ceedings of International Conference on Computational Intelligence, Modelling and Simulation. https://doi.org/10.1109/CIMSim.2012.65

11. Paisios, N. (2012). Mobile accessibility tools for the visually impaired. ProQuest Dissertations and Theses.

12. Ben Gesing, Peterson, S. J., \& Michelsen, D. (2018). Artificial Intelligence in Logistics - A collaborative report by DHL and IBM on implications and use cases for the logistics industry. DHL Customer Solutions \& Innovation.

13. McGookin, D., Brewster, S., \& Jiang, W. (2008). Investigating touchscreen accessibility for people with visual impairments. In Pro-ceedings of the 5th Nordic conference on Humancomputer interaction building bridges $\quad$ - NordiCHI '08. https://doi.org/10.1145/1463160.1463193

14. Jafri, R., Ali, S. A., Arabnia, H. R., \& Fatima, S. (2014) Computer vision-based object recognition for the visually impaired in an indoors environment: a survey. Visual Computer. https://doi.org/10.1007/s00371-013-0886-1

15. Khairallah, M., Kahloun, R., Bourne, R., Limburg, H., Flaxman, S. R., Jonas, J. B., ... Taylor, H. R. (2015) Number of people blind or visually impaired by cataract worldwide and in world regions, 1990 to 2010. Investigative Ophthalmology and Visual Science. https://doi.org/10.1167/iovs.15-17201

16. Leasher, J. L., Bourne, R. R. A., Flaxman, S. R., Jonas, J. B., Keeffe, J., Naidoo, K., ... Taylor, H. R. (2016). Global estimates on the number of people blind or visually impaired by diabetic retinopathy: A meta-analysis from 1990 to 2010. Diabetes Care. https://doi.org/10.2337/dc15-2171

17. Loomis, J. M., Golledge, R. G., Klatzky, R. L., Speigle, J. M., \& Tietz, J. (1994). Personal guidance system for the visually impaired. In Proceedings of the first annual ACM conference on Assistive technologies - Assets '94. https://doi.org/10.1145/191028.191051

18. Mahmud, N., Saha, R. K., Zafar, R. B., Bhuian, M. B. H., \& Sarwar, S. S. (2014). Vibration and voice operated navigation system for visually impaired person. In 2014 International Conference on Informatics, Electronics and Vision, ICIEV 2014.

https://doi.org/10.1109/ICIEV.2014.6850740

19. https://www.thebetterindia.com/140639/artificial-intellig ence-visually-impaired-drishti/

20. https://www.business-standard.com/article/economy-poli cy/govt-plans-to-launch-a-national-centre-for-artificial-in telligence-119012901188_1.html

21. https://www.businesstoday.in/magazine/the-buzz/get-setfor-the-bot-era/story/304060.html

22. https://www.businesstoday.in/magazine/the-buzz/schooli ng-them-differently/story/304056.html

23. https://www.businesstoday.in/magazine/the-buzz/the-fut ure-office/story/304038.html

24. Ahmad, P. A. (2015). Self-Confidence of Physically Challenged Viz Visually Impaired, Hearing Impaired and Orthopedically Impaired Secondary School Students of Kashmir Division, 5(7), 112-122. Retrieved from

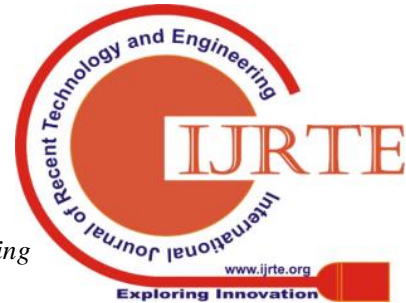


file:///C:/Users/toshiba/Downloads/21522-24282-1PB (1).pdf

25. Des, E., Unis, E., \& Washington, S. N. W. (2015). 12_Chapter 3.Pdf.

https://doi.org/10.1049/el.2014.1950

26. Stankov, L., Kleitman, S., \& Jackson, S. A. (2015).

Measures of the Trait of Confidence. In Measures of Personality and Social Psychological Constructs. https://doi.org/10.1016/B9780-12-386915-9.00007-3

27. https://www.thisisinsider.com/how-blind-people-use-sma rtphones-2017-2 